\title{
Effect of Reinforcement Particles on the Fluidity and Solidification Behavior of the Stir Cast Aluminum Alloy Metal Matrix Composites
}

\author{
Rabindra Behera ${ }^{1, *}$, D. Chatterjee ${ }^{2}$, G. Sutradhar ${ }^{3}$ \\ ${ }^{1}$ Dept. of Mechanical Engg., Jadavpur University, Kolkata, India \\ ${ }^{2}$ Dept. of Mechanical Engg. Bengal Engg. and Science University, India \\ ${ }^{3}$ Dept. of Mechanical Engg, Jadavpur University, Kolkata, India
}

\begin{abstract}
In the present work authors investigate the effect of weight percentage of SiCp on the fluidity and the rate solidification of stir cast MMCs. Experiments were carried out over range of particle weight percentage of 5.0-12.5 wt $\%$ in steps of $2.5 \mathrm{wt} \%$. Spiral castings and three-stepped castings of aluminum alloy (LM6) and its composites reinforced with different weight fractions $\mathrm{SiCp}$ have produced to study the fluidity of MMCs and solidification behavior of its castings by putting K-type thermocouples at the different step/section of the casting. The experimental results indicate that on increasing the weight percentage of reinforcement particles i.e. SiCp in cast aluminum alloy (LM6) MMCs the fluidity of cast composite metal decreases and the rate of solidification decreased due to which the total solidification time enhanced. This experimental result will offer good support for production of thin wall castings.
\end{abstract}

Keywords LM6, Sicp, Mmcs, Fluidity, Solidification

\section{Introduction}

Recently, metal-matrix composites (MMCs) have emerged as potential alternatives to conventional alloys in high-strength and stiffness applications[1]. But, the cost is the key factor for their wider application in automotive and aerospace industries, although potential benefits in weight saving, increased component life, and improved recyclability should be taken into account[2]. Today, even in those terms, MMCs are still significantly more expensive than their competitors. Only simpler fabrication methods, higher production volumes, and use of cheaper reinforcements[1] can reduce the cost of MMCs. There are several methods are used to manufacture aluminum alloy based metal matrix composites such as powder metallurgy (PM), where metal and ceramic powders are blended and hot-pressed[3], and liquid-state processes such as melt infiltration[4-8], compo casting, blending ceramic powder and molten aluminum and casting, melt stirring[9-15], pressurized infiltration and squeeze casting[16-30]. Out of which melt-stir casting technique is one of the cost effective and quite popular methods due to its unique advantages. In this technique, the reinforcement particles are introduced directly into the liquid

* Corresponding author:

rabi_lisha@yahoo.com (Rabindra Behera)

Published online at http://journal.sapub.org/materials

Copyright (C) 2012 Scientific \& Academic Publishing. All Rights Reserved melt and stirred the melt, at a suitable stirring speed thoroughly to ensure proper mixing of reinforcement particles with the matrix metal.

In liquid-metal casting method, the production of thin wall section castings of aluminum alloy metal matrix composite is a challenge for the foundry engineers. As rapid cooling of thin wall sections of the casting reduces the fluidity of the molten metal, which could cause the molten metal to premature freeze before it can completely fill the mold cavity, resulting in an incomplete mold fill or cold shuts. Hence, one of the key factors has to be taken into account in foundry practice of thin section casting is the fluidity. The fluidity of $\mathrm{Al}$ alloy/SiCp composites has a direct influence not only on material castability, but also on the casting properties, due to which a thorough knowledge on different factors that affecting the fluidity of MMCs is essential.

Another point of concern with respect to the properties of cast metal matrix composites is the properties of cast MMCs produced by stir cast method has influenced by various parameters such as type, size \& weight fraction of reinforcement particles and its distribution in matrix metal. It also depends on their solidification behavior during casting. The rate of solidification has a significant effect on the microstructure of cast composites, which in turn affects their mechanical properties. Nath et al.[31] studied the mica particle distribution in $\mathrm{Al}-\mathrm{Cu}-\mathrm{Mg}$ melt solidified in a variety of moulds under different heat flow configurations and concluded that thin castings of $12.5 \mathrm{~mm}$ could easily be pro- 
duced with a homogeneous distribution of mica particles. Rohatgi et al.[32] studied on the segregation of silicon carbide particles by settling and particle pushing in cast $\mathrm{Al} 357$ 15 vol. \% SiCp composites under various solidification conditions. They concluded that the best distribution of particles obtained under fast cooling rate during multidirectional cooling. Dutta and Surappa[33] studied macro- and micro-structure of $\mathrm{Al}-\mathrm{Cu}-\mathrm{SiCp}$ composites under multidirectional solidification conditions and concluded that an increase in particle volume fraction and cooling rate reduced the extent of macro-segregation of reinforcements in the composites. Eardley and Flower[34] studied the temperature development during infiltration and solidification stage of casting commercial aluminum matrix composites. The results indicated that the final macro- and micro-structures of the material were strongly dependent on the temperature profile. T.P.D. Rajan et al.[35] studied on solidification and casting / mould interfacial heat transfer characteristics of aluminum matrix composite. They have shown that, addition of ceramic reinforcement particles with the aluminum alloy reduces the total solidification time in all the moulds (i.e. sand, graphite and metal mould) at lower volume fractions and increases at higher volume fractions. They also concluded that the total solidification time was very less in case of graphite mould comparison to steel and sand mould, because of high thermal conductivity of graphite.

The present paper investigates the fluidity and solidification behavior of matrix metal at different weight fraction of $\mathrm{SiCp}$. The effect of weight fraction of SiCp on the fluidity evaluated by means of spiral test and the rate of solidification of cast metal matrix composites have measured at different step of the casting by using Data Acquisition System (DAS). The results are compared with the unreinforced matrix metal i.e. LM6.

\section{Fluidity of Cast Metal}

Fluidity is a complex technological phenomenon, in foundry. Fluidity tests have been developed and are used commercially as quality checks to determine the flowing qualities of molten metal[36]. Fluidity, in casting terminology; is used to indicate the distance a molten metal can flow before it solidifies in the mould cavity[37-39].Fluidity is therefore a length, usually in millimeters or meters. It is an important property for casting alloys and determines the ability of the liquid metal to fill the mold cavity. The term Fluidity has come to a meaning quite different to the foundry man than to the physicist. To the physicist, it is the reciprocal of viscosity; to the foundry man, it is an empirical measure of a processing characteristic[40]. Fluidity, in the casting sense, refers to the property of a metal, which allows it to flow when it has poured into a standard fluidity test channel. This channel may be straight or it may be in the form of a spiral, the cross-section may be round, half round, trapezoidal, or rectangular.

There are number of factors affecting the fluidity of cast
MMCs, such as-:

i. Metallurgical variables, such as composition, superheat, latent heat, surface tension, viscosity and mode of solidification.

ii. Mold/casting variables, such as part configuration, cooling rate, degree of super heat, mold material and its surface characteristics.

iii. Test variables, such as applied metal head, channel diameter, casting temperature (super heat) and oxide/particle content.

In addition, reinforcement characteristics such as size, shape and its weight fraction affect the fluidity behavior of metal matrix composite melts. Cooksey et al.[41] investigated the effect of major impurities on the casting fluidity of pure $\mathrm{Al}$ observed a marked change in the casting fluidity between super pure $(99.9 \%)$ and commercially pure $\mathrm{Al}$ (99.7\%).The major contributor towards decrease in casting fluidity is $\mathrm{Si}$; the influence of $\mathrm{Fe}$ is small, while that of $\mathrm{Ti}$ is intermediate. The large difference of casting fluidity observed between the high purity and the commercial $\mathrm{Al}$ is due to the presence of $\mathrm{Si}$, which changes the mode of solidification from skin forming to equiaxed growth. The alloys studied can be classified into two groups: (i) alloys not containing Si having good fluidity and columnar structures and (ii) alloys containing Si having low fluidity and equiaxed structures. Gowri and Samuel[42] investigated the fluidity of A380 die casting alloy and observed that an increase in the Fe content decreases the fluidity of the alloy. Addition of 1.5 and $1.7 \mathrm{wt} \% \mathrm{Fe}$ to the $\mathrm{A} 380$ alloy caused 4 and $6 \%$ decrease in fluidity, respectively while the addition of $1.3 \mathrm{wt} \% \mathrm{Zn}$ to the 380 alloy caused $5 \%$ decrease. However, addition of $1 \mathrm{wt} \%$ $\mathrm{Cu}$ to the 380 alloy caused $4 \%$ increase. No significant change in the fluidity of the $\mathrm{A} 380$ alloy was observed when 0.23 and $0.5 \mathrm{wt} \% \mathrm{Mg}$ was added. Rooy[43] and Wang et al.[44] also reported similar reductions in fluidity of Al-Si-based foundry alloys with increasing Fe. These observations, however, contradicted those of Pfeiffer and Sabath[45], who observed increased fluidity of $\mathrm{Al}-8 \mathrm{Si}-3 \mathrm{Cu}$ alloy as the total combined concentrations of $\mathrm{Fe}, \mathrm{Mn}$ and $\mathrm{Zn}$ increased. Chai[46] observed that the addition of certain alloying elements alters the dendrite coherency point of the solidifying melt and hence affects fluidity. Coherency occurs when the secondary dendrite arms of the growing equiaxed crystals impinge upon one another and begin to form a solid network of grains[47,48]. Delays to coherency may tend to increase fluidity as a result of the increased time available for mass feeding. Limited experimental results are available to substantiate this hypothesis, although initial indications appear to support the claim. Lloyd[49] found that the A356-10 vol. \% SiC composite produced by Duralcan had a spiral length comparable to the particle free standard alloy, and the spiral length increased with temperature up to $750^{\circ} \mathrm{C}$. In addition, A356-20 vol. \% SiC showed similar behavior up to $710^{\circ} \mathrm{C}$. However, at higher temperatures, its spiral length decreases with decreasing temperature. Kolsgaard[50] found that the fluidity length, measured with a spiral test in sand mold, increased linearly by increasing superheat. An in- 
crease by $1{ }^{\circ} \mathrm{C}$ in the melt temperature gave an increase of $1 \%$ in the fluidity length, in the temperature interval $700-760^{\circ} \mathrm{C}$. Sahoo and Sivaramakrishnan[51] measured the fluidity of an Al-8.3Fe-0.8V-0.9Si alloy with standard spiral test in sand mold and reported an increase of $0.4 \%$ in the fluidity length when the melt temperature was increased by $1^{\circ} \mathrm{C}$, in the temperature interval of $860-900^{\circ} \mathrm{C}$. Yarandi et al.[52] found that the A356 alloy-SiCp composite(cast in a permanent mold) containing 15 vol. $\%$ SiCp of $9 \mu$ mdiameter had the lowest flowability, lower than that of composite containing 20 vol. $\%$ SiCp of $14 \mu \mathrm{m}$ diameter, indicating that particle size has a strong influence on flow and spiral length. The decrease with size has been attributed to an increase in the total surface area of particulates causing more resistance to fluid flow as a result of stagnant boundary layers around the particles. Surappa and Rohatgi[53] observed that spiral fluidity tested in a permanent mold casting decreased linearly with the total surface area per unit weight of the particles.

In this investigation the fluidity of aluminum alloy i.e.LM6 containing 5-12.5 $\mathrm{wt} \% \mathrm{SiC}$ particles in the steps of $2.5 \mathrm{wt} \%$ has measured by means of spiral casting. The fluidity test results of the composites have been compared with that of the base alloy to assess the ability of the composite melt containing particles to flow and fill the spiral mold cavity during casting.

\section{Experimental Procedure}

The aluminum-silicon alloy i.e.LM6, which is a well known alloy of aluminum, is used as the base/matrix metal in the experiments for the fabrication of the composites that has been reinforced with $5 \mathrm{wt} \%, 7.5 \mathrm{wt} \%, 10 \mathrm{wt} \%$ and $12.5 \mathrm{wt} \%$ of SiCp of average 400 mesh size. The chemical composition of the matrix material (LM6) and the thermo physical properties of aluminum alloy, SiCp \& sand have given in the table-1 \& table-2. The composites have been fabricated by the liquid metal stir casting technique. The aluminum alloy is melted in clay graphite crucible using an electric resistance furnace and 3wt.\% Mg has been added with the liquid metal, in order to achieve a strong bonding by decreasing the surface energy (wetting angle) between the matrix alloy and the reinforcement particles. The addition of pure magnesium has also enhanced the fluidity of the molten metal. The melt has mechanically stirred by using an impeller after addition of the pre-heated silicon carbide particle (about $850-900^{\circ} \mathrm{C}$ ). The processing of the composite has carried out at a temperature of $750^{\circ} \mathrm{C}$ with a stirring speed of $400-500 \mathrm{rpm}$. The melt has poured at a temperature of $745^{\circ} \mathrm{C}$ into spiral mold and stepped silica sand mold.

The pattern and the sand mold for spiral test have shown in the Fig.1. A match plate pattern has used to prepare the spiral sand mold. The molten metal has poured into the skin dried resin bonded spiral sand mold at the centre of the spiral and the pouring temperature of molten metal maintained at $720-730^{\circ} \mathrm{C}$, to measure the fluidity of the cast MMCs at different weight fraction of the reinforcement particles.

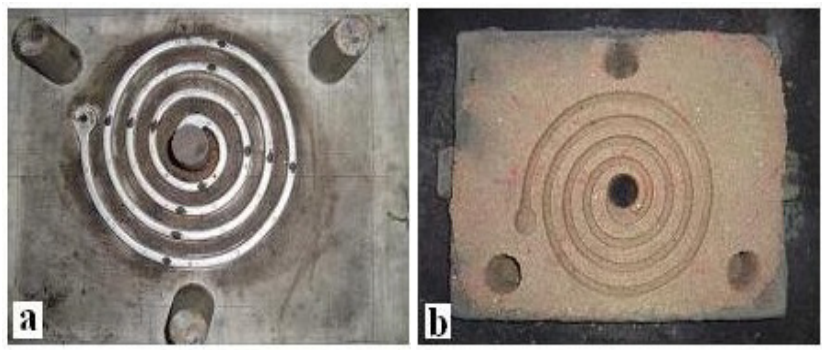

Figure 1. Schematic diagram of: (a) Match plate spiral pattern; (b) Resin bonded spiral sand mold

To study the solidification behavior of cast MMCs at different modulus of the casting, three (i.e. $\mathrm{T}_{1}, \mathrm{~T}_{2} \& \mathrm{~T}_{3}$ ) K-type thermocouples of $3.0 \mathrm{~mm}$ size has been inserted at the centre of the different section (step) of the mold to measure the temperature variation in the casting during solidification as shown in Fig.2. One more K-type thermocouple has inserted into the sand to measure the temperature variation of the molding sand after pouring of molten metal and during solidification of the castings. The solidification curves of the castings and the variation of temperatures at different sections in the mold has been recorded with the help of a computer aided data acquisition system, the schematic sketch of the computer aided temperature data acquisition set up as shown in Fig.3. Experiments carried out for a wide range of particle weight percentage varying from $5 \%$ to $12.5 \%$ in steps of $2.5 \%$. Finally, the solidification curves of LM6- SiCp composites have been compared with the unreinforced LM6 matrix alloy at different section of the casting. The micro structural characteristics of the alloys and composites at different section of the castings have also been evaluated.

Table 1. Chemical Composition (LM6)

\begin{tabular}{|c|c|c|c|c|c|c|c|c|c|c|c|}
\hline Elements & $\mathrm{Si}$ & $\mathrm{Cu}$ & $\mathrm{Mg}$ & $\mathrm{Fe}$ & $\mathrm{Mn}$ & $\mathrm{Ni}$ & $\mathrm{Zn}$ & $\mathrm{Pb}$ & $\mathrm{Sb}$ & $\mathrm{Ti}$ & $\mathrm{Al}$ \\
\hline Percentage (\%) & $10-13.0$ & 0.1 & 0.1 & 0.6 & 0.5 & 0.1 & 0.1 & 0.1 & 0.05 & 0.2 & Remaining \\
\hline
\end{tabular}

Table 2. Thermo physical properties of Matrix metal, Reinforcement particle and Sand

\begin{tabular}{|c|c|c|c|}
\hline Properties & LM6 & SiC particulates & Sand \\
\hline Density $\left(\mathrm{gm} / \mathrm{cm}^{3}\right)$ & 2.66 & 3.2 & 1.6 \\
\hline Average particle size $(\mathrm{mesh})$ & --- & 400 & --- \\
\hline Thermal conductivity $(\mathrm{W} / \mathrm{m}-\mathrm{K})$ & 155 & 100 & 0.52 \\
\hline Specific heat $(\mathrm{J} / \mathrm{Kg}-\mathrm{K})$ & 960 & 1300 & 1170 \\
\hline
\end{tabular}




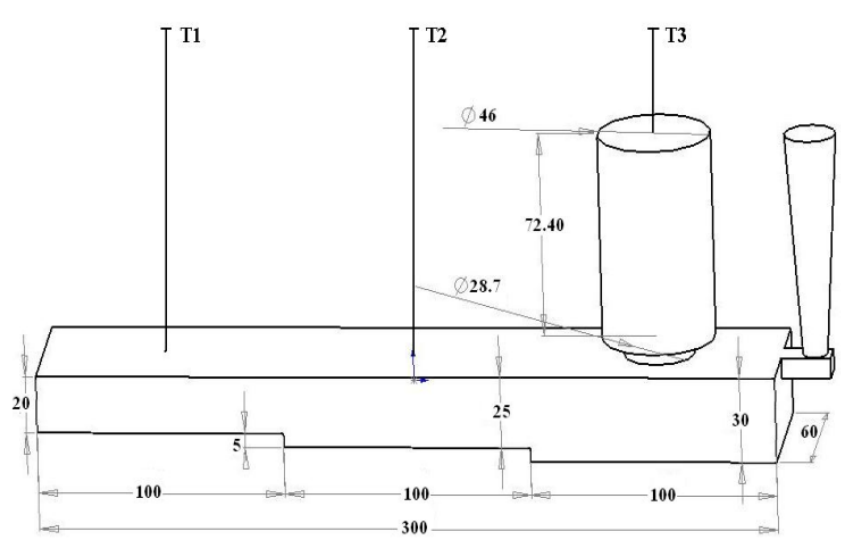

(All dimensions are in $\mathrm{mm}$ )

Figure 2. The $3 \mathrm{D}$ geometry of mould cavity with K-thermocouples $\left(\mathrm{T}_{1}, \mathrm{~T}_{2} \& \mathrm{~T}_{3}\right)$

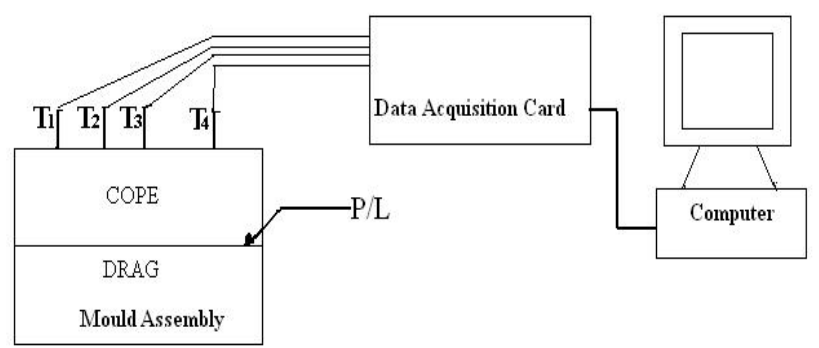

$\left(\mathrm{T}_{1}, \mathrm{~T}_{2} \& \mathrm{~T}_{3}\right.$ Thermocouples connected with different section of casting and $\mathrm{T}_{4}$ inserted into the)

Figure 3. Schematic sketch of the computer aided temperature data acquisition set up

\section{Results and Discussion}

\subsection{Fluidity Measurement}

Fluidity is an important parameter in metal casting, that affected by number of factors. Fluidity properties of aluminum alloy significantly changes after addition reinforcement particles, this change in fluidity due to change in viscosity. The highest fluidity is commonly associated with short range alloys, such as pure metals and eutectic alloys, where solidification takes place by the advance of plane interface. When the liquid metal contains a dispersion of particles, the effective or apparent viscosity rises markedly above the viscosity of pure (monolithic) melts. For extremely dilute suspensions (solid volume fraction, $\varphi<0.1$ ), the effective viscosity, $\mu \mathrm{c}$, of the suspension can be predicted using Einstein equation[54],

$$
\mu_{\mathrm{c}}=\mu_{0}\left(1+2.5 v_{f}^{2}+10.25 v_{f}^{2}\right)
$$

Where, $\mu_{\mathrm{c}}$ is the apparent viscosity of composite slurries $(\mathrm{g} / \mathrm{cm} \mathrm{s}), \mu_{\mathrm{o}}$ the viscosity of fluids without any particle $(\mathrm{g} / \mathrm{cm}$ s) and $v_{f}$ is the volume fraction of the suspended particles.

The casting for fluidity test (spiral castings) is shown in Fig. 4; this shows the fluidity i.e. the spiral length of the matrix alloy i.e.LM6 and composites at different weight percentage of SiCp. The Fig.5, shows that the effect of weight percentage of $\mathrm{SiCp}$ on the fluidity. The total spiral length $126 \mathrm{~cm}$ for LM6 casting and the spiral lengths are102, 97.5, 91 and $85 \mathrm{~cm}$ for LM6 metal matrix composites rein- forced with 5, 7.5,10 and $12.5 \mathrm{wt} \%$. The fluidity length of the composites is shorter than that of the LM6 base material. In spiral mold, the fluidity length has shortened when the weight percentage of $\mathrm{SiCp}$ content increased in the base metal i.e LM6. This is because increasing the $\mathrm{SiC}$ particulate content tends to form $\mathrm{Al}_{4} \mathrm{C}_{3}$ in the interface; as a result, the viscosity is increased and the fluidity of the melt composites decreased. Surappa and Rohatgi[53] and Carity[55] reported the similar trend in case of permanent mold casting.

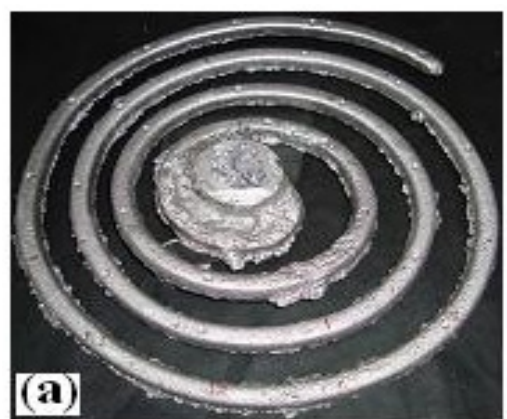

a. LM6

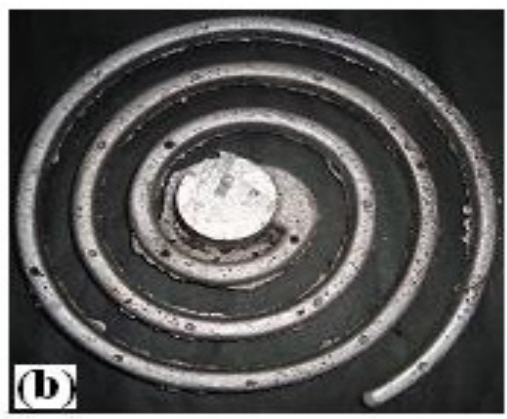

b.LM6/5wt $\% \mathrm{SiCp}$

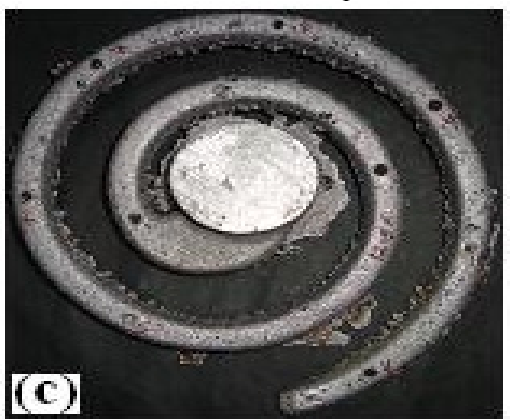

c. LM6/12.5wt $\% \mathrm{SiCp}$

Figure 4. Spiral cast of LM6, LM6/5wt $\% \mathrm{SiCp}$ and LM6/12.5wt $\% \mathrm{SiCp}$

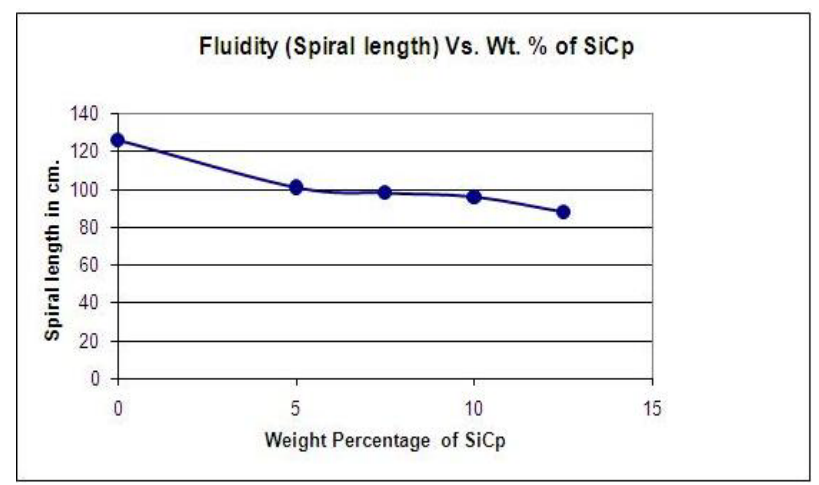

Figure 5. Effect of weight percentage of $\mathrm{SiCp}$ on the fluidity of metal matrix composites 


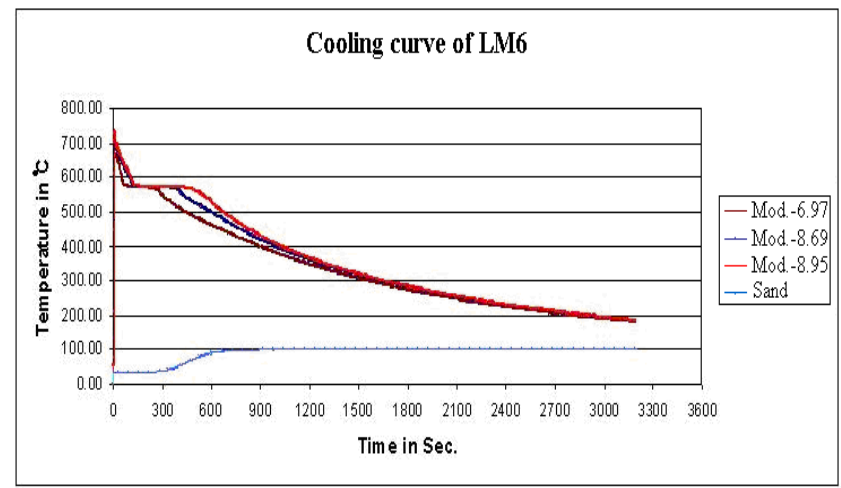

Figure 6. Cooling curves of $\mathrm{Al}$ (LM6) composites at different modulus of the casting

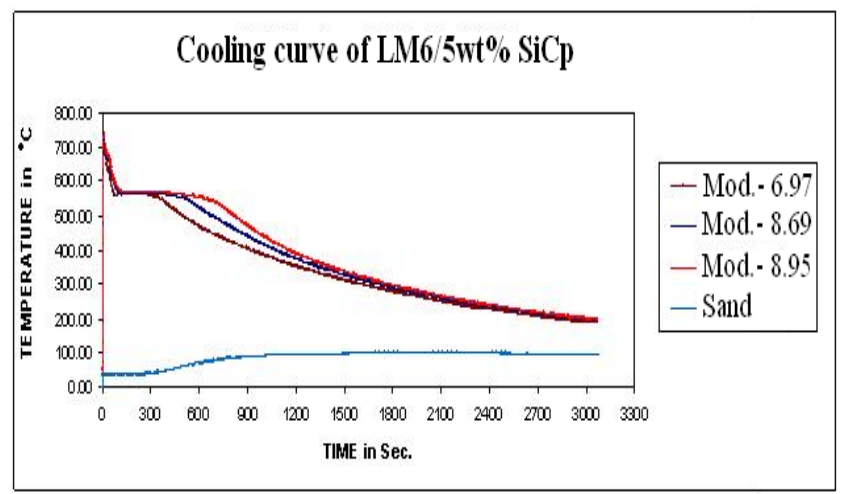

Figure 7. Cooling curves of $\mathrm{Al}(\mathrm{LM} 6)-5 \mathrm{wt} \% \mathrm{SiC}$ composites at different section of casting

\subsection{Cooling Curves and Solidification}

Addition of an alloying element or second phase particles into a matrix alloy usually affects the various time and temperature parameters of its solidification curve. The variation in the nature of the cooling curve always has a significant impact on the microstructure and mechanical behavior of the material. Fig.6-10 shows the cooling curve of the $\mathrm{Al}$ alloy (LM6) and LM6 reinforced with $5 \mathrm{wt} \%, 7.5 \mathrm{wt} \%$, $10 \mathrm{wt} \%$ and $12.5 \mathrm{wt} \%$ of $\mathrm{SiCp}$ metal matrix composites. The cooling curves for different section of castings at different weight fraction of $\mathrm{SiCp}$ indicate that the rate of cooling increasing on increasing the weight percentage of SiCp in the cast MMCs. The cooling rate from the cooling curves shows that the eutectic solidification time (i.e. the time interval between the start and the end of the eutectic phase solidification) increases on increasing the weight percentage of $\mathrm{SiC}$ particles in the aluminum alloy matrix. It has also observed that the introduction of $\mathrm{SiC}$ particles in the matrix metal lowered the liquidus temperature when compared with the unreinforced alloy. Fig.11 shows the variation of liquidus temperature with increase in weight percentage of $\mathrm{SiC}$ particle. This can be attributed to the unfavorable primary aluminum nucleation condition prevailing at the reinforcement surface and the depression in the freezing point due to the presence of reinforcement, which is considered as an impurity. Studies by Gowri and Samuel[56] have also shown that addition of particles lowers the liquidus temperature by about $10^{\circ} \mathrm{C}$. The similar trend has also observed by T.P.D.
Rajan et al.[35].It is observed that the start of eutectic solidification of the matrix alloy (LM6) at a temperature of $574^{\circ} \mathrm{C}$ with the solidification ending at $572^{\circ} \mathrm{C}$. After addition of reinforcement particles i.e. SiCp in matrix alloy, the start and end temperature of eutectic solidification changes.

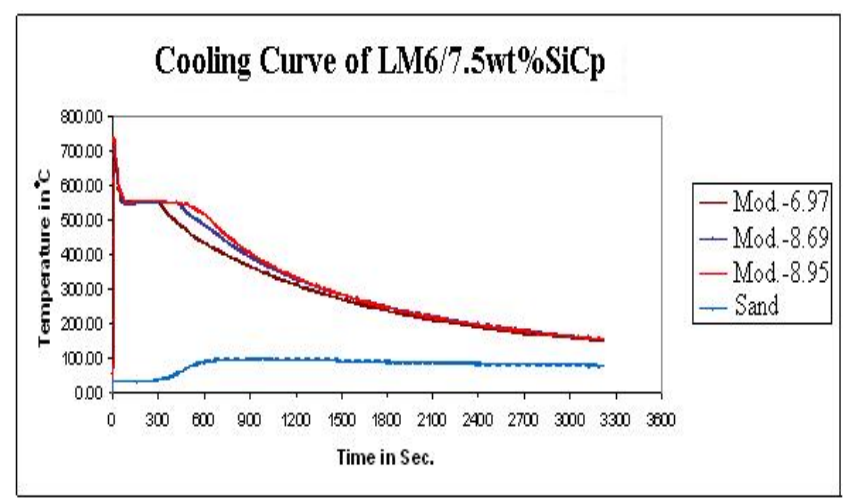

Figure 8. Cooling curves of $\mathrm{Al}(\mathrm{LM} 6)-7.5 \mathrm{wt} \% \mathrm{SiC}$ composites at different section of casting

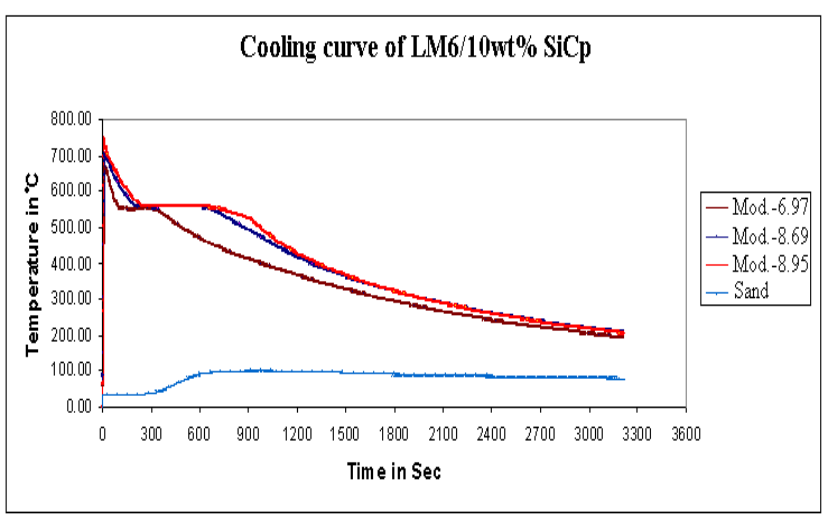

Figure 9. Cooling curves of $\mathrm{Al}$ (LM6)-10wt $\% \mathrm{SiC}$ composites at different section of casting

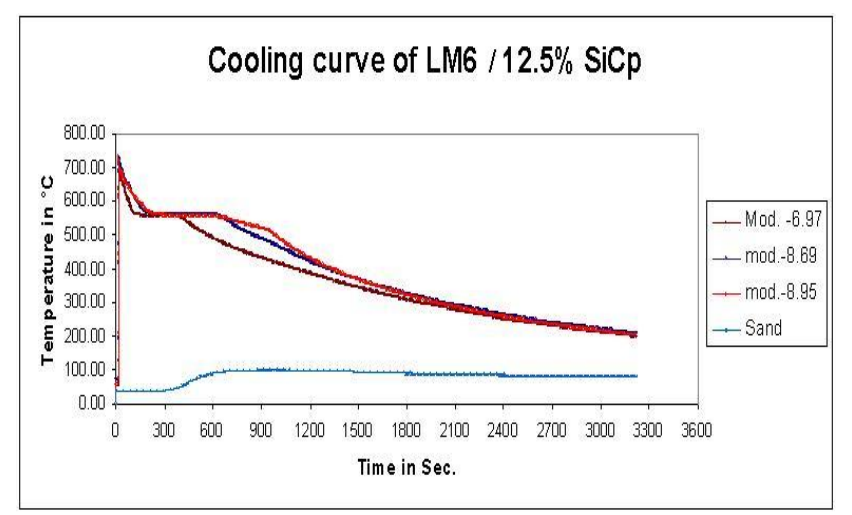

Figure 10. Cooling curves of $\mathrm{Al}(\mathrm{LM} 6)-12.5 \mathrm{wt} \% \mathrm{SiC}$ composites at different section of casting

The addition of SiCp, increasing the eutectic solidification time as compared with the cooling curve of aluminum alloy (LM6). The eutectic solidification time also changed with the modulus of the casting, the cooling curve indicates that on decreasing the section modulus of the MMC castings the eutectic solidification time decreases at different weight fraction of $\mathrm{SiC}$ particles i.e. in case of lowest modulus the eutectic solidification time is less compared to highest 
modulus. This validates that the Chvorinov's rule still applies to the solidification process, irrespective of what additives are added to the molten metal[57,58]. The cooling curve shows that the eutectic solidification time is enhanced on increasing the weight fraction of reinforcement particles compared to unreinforced matrix alloy. Fig. 12 shows the variation in eutectic solidification time with respect to different weight percentage of SiCp and at different modulus of the castings. It has been observed that on increasing the weight percentage of $\mathrm{SiCp}$ in the cast $\mathrm{Al}$ alloy (LM6) metal matrix composites the eutectic solidification time increases at different modulus of the castings. That means the total solidification time (i.e. the time interval between the start of primary aluminum phase nucleation and the end of the eutectic phase solidification) increases on increasing wt $\%$ of $\mathrm{SiCp}$. This trend may be attributed to the fact that the amount of heat extraction reduced on increasing the weight percentage of $\mathrm{SiC}$ particles in the liquid matrix metal as the presence of $\mathrm{SiC}$ particles in the matrix metal reduced the thermal conductivity and thermal diffusivity[35].

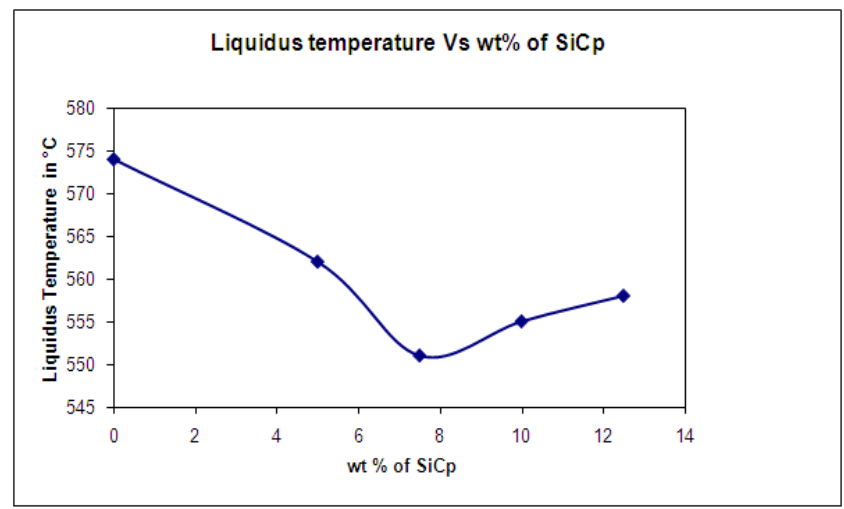

Figure 11. Effect of $\mathrm{wt} \% \mathrm{SiCp}$ on liquidus temperature

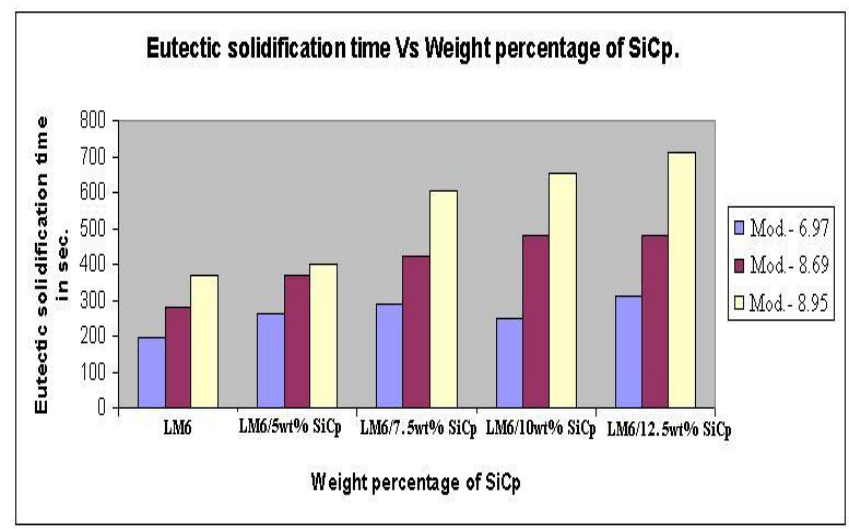

Figure 12. Effect of $w \mathrm{t} \% \mathrm{SiCp}$ on eutectic solidification time

\subsection{Microstructural Analysis}

Samples of as cast MMCs for metallographic examination were prepared by grinding through $320,400,600,800,1200$ and 1500 grit papers followed by polishing with $6 \mu \mathrm{m}$ diamond paste. Then the samples were etched with the etchant i.e. Keller's reagent $(2.5 \mathrm{ml}$ Nitric acid, $1.5 \mathrm{ml} \mathrm{HCl}, 1.0 \mathrm{ml}$ HF, $95.0 \mathrm{ml}$ Water). The etched samples were dried by using electric drier and then the microstructure was observed by using optical microscope (Olympus, modelno.-GS51).The microstructure of the as cast LM6 MMCs are shown in figure-13 -16 at different modulus of the casting. The micrograph of MMC castings at different section shows that the distributions of $\mathrm{SiC}$ particles are not uniform throughout the casting and segregation of particles are more in the eutectic region. This tendency may be attributed to the fact that the rate of cooling is not uniform throughout the casting due to change in thickness of the casting and slower rate of cooling in the sand mold.
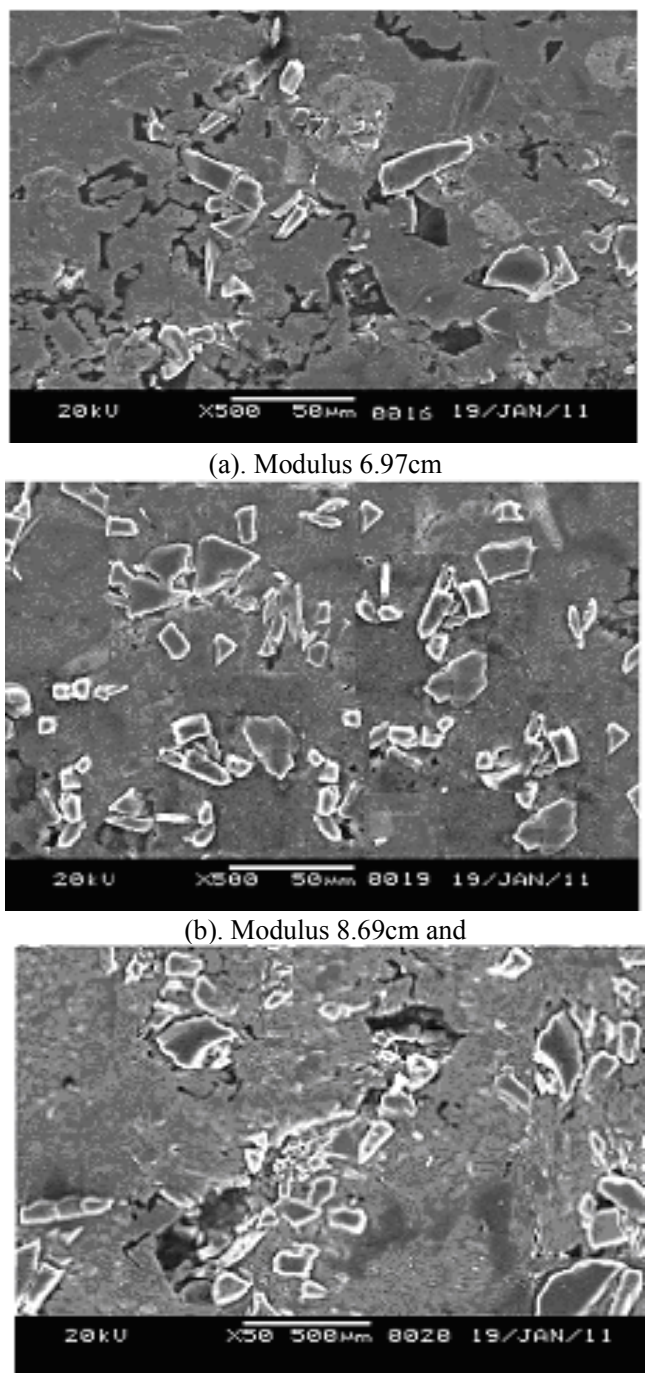

(c). Modulus $8.95 \mathrm{~cm}$

Figure 13. Microstructure of $\mathrm{LM} 6 / 5 \mathrm{wt} \% \mathrm{SiCp}$ as cast $\mathrm{MMC}$ at different modulus of the casting

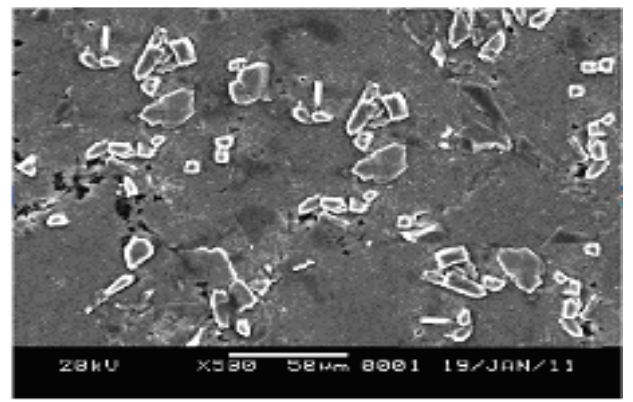

(a). Modulus $6.97 \mathrm{~cm}$ 


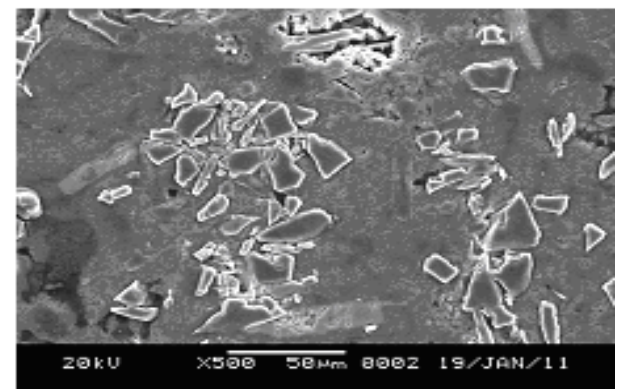

(b). Modulus $8.69 \mathrm{~cm}$ and

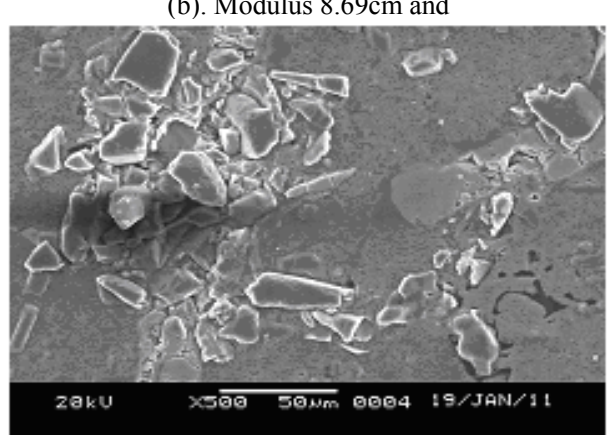

(c). Modulus $8.95 \mathrm{~cm}$

Figure 14. Microstructure of $\mathrm{LM} 6 / 7.5 \mathrm{wt} \% \mathrm{SiCp}$ as cast $\mathrm{MMC}$ at different modulus of the casting

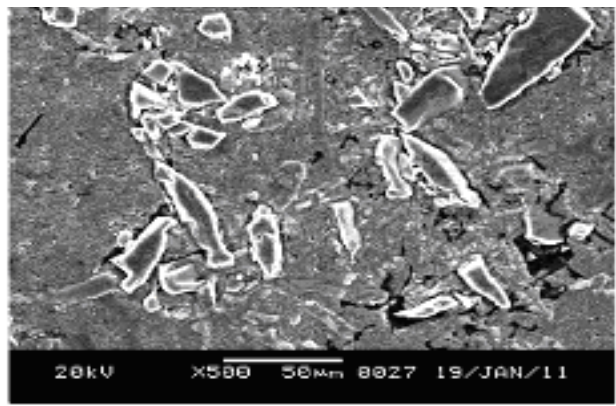

(a). Modulus $6.97 \mathrm{~cm}$

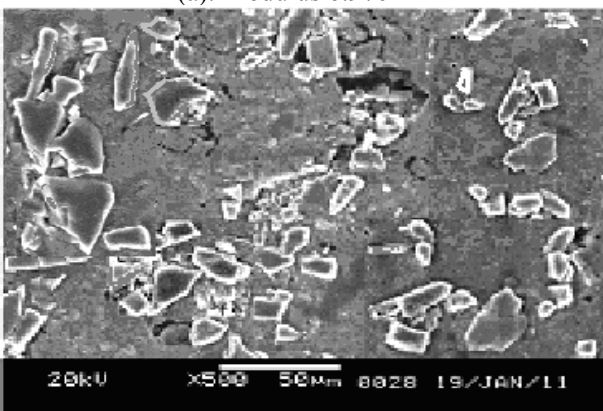

(b). Modulus $8.69 \mathrm{~cm}$ and

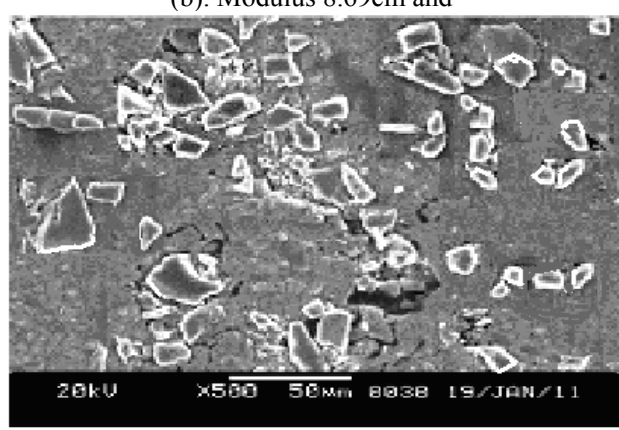

(c). Modulus $8.95 \mathrm{~cm}$

Figure 15. Microstructure of $\mathrm{LM} 6 / 10 \mathrm{wt} \% \mathrm{SiCp}$ as cast MMC at different modulus of the casting
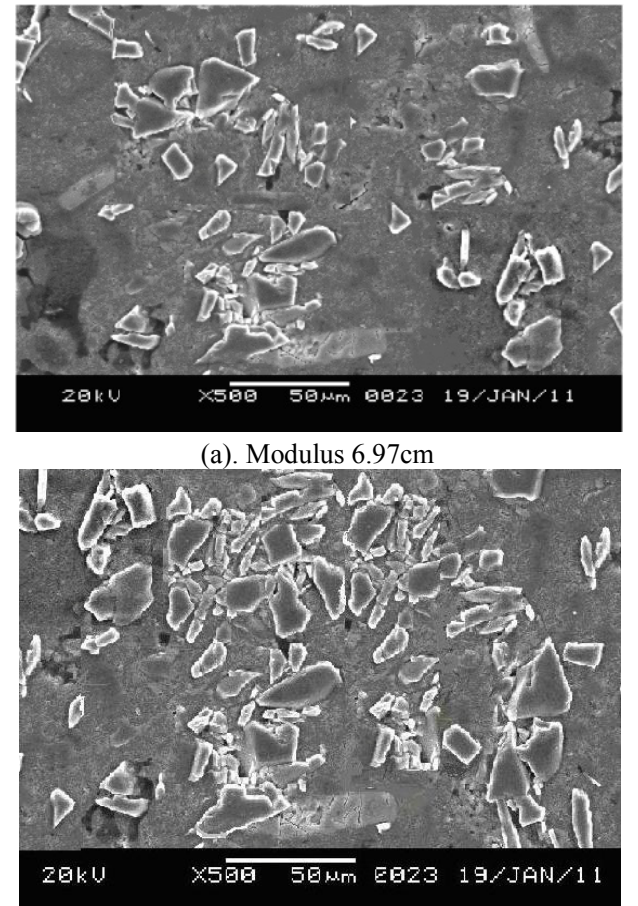

(b). Modulus $8.69 \mathrm{~cm}$ and

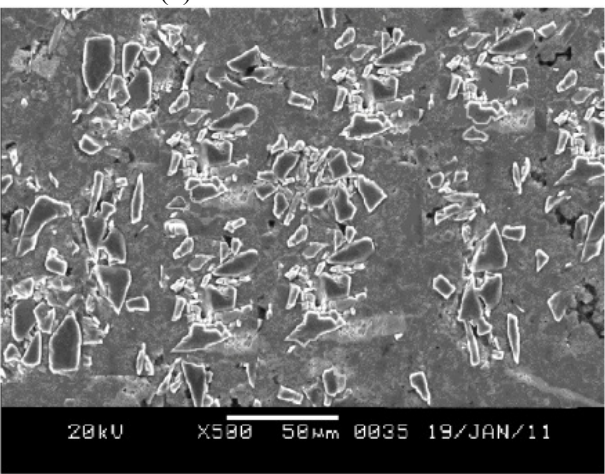

(c). Modulus $8.95 \mathrm{~cm}$

Figure 16. Microstructure of LM6/12.5 wt $\% \mathrm{SiCp}$ as cast MMC at different modulus of the casting

\section{Conclusions}

In this experimental study the effect of $\mathrm{SiC}$ particles on the fluidity properties of the metal matrix composites are measured by means of spiral casting. The solidification behavior of cast MMCs are also studied through the cooling curves that recorded experimentally for Al alloy (LM6) with varied percentage of $\mathrm{SiC}$ particles from $5 \mathrm{wt} \%$ to $12.5 \mathrm{wt} \%$ in steps of $2.5 \mathrm{wt} \%$ and compared with the unreinforced matrix alloy.i.e.LM6.

- The fluidity test reveals that on increasing the weight percentage of $\mathrm{SiC}$ particles in matrix metal the spiral length decreases comparison to the matrix metal. This may be due to increase in viscosity of the composite melts.

- The cooling rate increases with the introduction of $\mathrm{SiCp}$ with increasing $\mathrm{SiCp}$ content in the matrix metal. It has also been observed that the introduction of $\mathrm{SiC}$ particles in the matrix metal have lowered the liquidus temperature compared with the unreinforced alloy. 
- Addition of ceramic reinforcement to alloy enhances the eutectic solidification time, as the presence of insulating dispersoids i.e. SiCp plays a dominant role in reducing the cooling rates. The solidification time has also varied with the change in modulus of castings. The solidification time decreases on decreasing the modulus of the castings. This trend is similar to the monolithic metal and its alloys.

\section{ACKNOWLEDGEMENTS}

Authors thankfully acknowledge the financial support provided by U.G.C, New Delhi under Major Research Project Grant[F.No.32-88/ 2006 (SR) dated 09.03.2007] without which this work could not be attempted.

\section{REFERENCES}

[1] D. Charles, 1990, Metal matrix composites-ready for take-off? Methods Mater. 6, 78-82

[2] T. F. Klimowicz, 1994, The large scale commercialization of aluminum-matrix composites, JOM 46,49-53

[3] Zamzam M, Ros D and Grosch J., 1993,Key Engng Mater, 79-80:235-46

[4] Xi XM, Xiao LM, Yang XF.,1996, J Mater Res Soc., 11(4) 1037

[5] Mortensen A, Michaud VJ, Flemings MC.,1993,J Metals, 36,35

[6] Das AA, Yacoub MM, Zantout Z, Clegg A. ,1988,J. Cast Metals, 1, (2),69

[7] Verna SK, Dorcic JL. Cast reinforced metal composites. In: Fishman SG, Dhingra AK, editors Materials Park, OH: ASM International, p. 115

[8] Fukunaga H.,1988, In: Fishman SG, Dhingra AK, editors. Cast reinforced metal composites. Materials Park, OH: ASM International.

[9] Leon CA, Drew RAL.,2000, J Mater Sci,35,4763

[10] Flemings MC, 1991,Metall Trans;22A:957

[11] Ray S.,1993, J Mater Sci,28,5397

[12] Rohatgi PK, Asthana R, Das S.,1986, Int Mater Rev, $31(3) 115$

[13] Llyod DJ., 1994, Int Mater Rev,39(1),1

[14] Srivatson TS, Ibrahim IA, Mohamed FA, Lavernia EJ., 1991, J Mater Sci, 26,5965-78

[15] Sing M, Jha AK, Das S, Yegneswaran AH.,2000, J Mater Sci,35 4421-6

[16] Mortensen A, Cornie JA, Flemings MC.,1989, Metall Trans;A20, 25-38
[17] Masur LJ, Mortensen A, Cornie JA, Flemings MC.,1989,Metall Trans; A20:2549

[18] Candan E, Atkinson HV, Jones H., 2000,J Mater Sci, 354953-9

[19] Cook AJ, Werner PS. Mater Sci Engng. A144,189-204

[20] Yang J, Chung DDL.,1991， J Mater Sci., 24 (1989),3605

[21] Maxwell B, Martins GP, Olson DL, Edward GR.,1990, Metall Trans, 21B,475

[22] Assar AM., 1999, J Mater Proc Tech., 86,152

[23] Alonso A, Pamies A, Narciso J, Garcia-Cordovilla C, Louis E., 1993, Metall Trans, 24A, 1423-32

[24] Warrier SG, Lin RJ.,1993,Scr Metall Mater., 29,1513

[25] Clyne TW, Mason JF.,1987, Metall Trans A,95

[26] Fukunaga H, Goda K.,1984, Bull JSME, 27,(228):1245

[27] Donomoto T, Miura N, Funatani K, Miyake N.,1983, SAE tech paper no.83052. Detroit, MI: Society of Automotive Engineers

[28] Aghajanian MK, Rocazella MA, Burke JT, Keck SD.,1991, J Mater Sci, 26, 447-54

[29] Martins GP, Olsen DL, Edwards GR.,1988, Metall Trans.,19B,95

[30] Canul MI, Katz RN, Makhlouf MM, Pickara S.,2000, Mater Sci.,;35: 2167-73

[31] Nath, D., Asthana, R., Rohatgi, P.K., 1987, Particle distribution control in cast aluminium alloy-mica composites. J. Mater. Sci., 22, 170-176

[32] Rohatgi, P.K., Yarandi, F.M., Liu, Y., Asthana, R., 1991, Segregation of silicon carbide by settling and particle pushing in cast aluminium-silicon-carbide particle composites. Mater. Sci. Eng. A, 147L1-L6

[33] Dutta, B., Surappa, M.K., 1998, Microstructure evolution during multidirectional solidification of $\mathrm{Al}-\mathrm{Cu}-\mathrm{SiC}$ composites. Composites, 29A, 565-573

[34] Eardley, E.S., Flower, H.M., 2003, Infiltration and solidification of commercial purity aluminium matrix composites. Mater. Sci. Eng. A, 359, 303-312

[35] Rajan, T.P.D., Narayana Prabhu, K., Pillai, R.M., Pai, B.C., 2007, Solidification and casting/mould interfacial heat transfer characteristics of aluminium matrix composites. Compos. Sci. Technol., 67, 70-78

[36] T. West., 1902, Metallurgy of Cast Iron,7th Edition.Cleveland: Cleveland Printing Company

[37] Hayashi, S., 1921, Investigation of the Fluidity of Metals and Alloys. In Memoires of Kyoto College of Engineering (p. 83). Kyoto: Kyoto Imperial University Press

[38] Flemings, M., Niiyama, E., \& Taylor, H., 1961, AFS Tarns, $69,625-635$

[39] Flemings, M., Niiyama, E., Niiyama, E., \& H.F., T., 1962, AFS Trans., 70, 1029-1039

[40] Cooksey, C.J., Kondic, C.V., 1959, the Casting Fluidity of 
Some Foundry Alloys. In The British Foundryman, 52 (p. 31)

[41] Cooksey, C.J., Kondic, C.V. and Wiclcock, J. J., 1959, Inst. Br. Foundrymen, 52, 381

[42] Gowri, S.and Samuel, F.H., 1994, Met. Trans. A, 25A, 437-448

[43] Rooy, E.L., 1985, AFS Trans., 93, 935-938

[44] Wang, L., Makhlouf, M. and Apelian, D., 1995, Int. Mater. Rev., 40 225-252

[45] Pfeiffer, W.D., Sabath, G. and Banyasz. Kohasz., 1986,Lapok., 37,39-43

[46] Chai, G.and Metallkd, Z., 1995, 86 (1) 54-59

[47] Dahle, A.K.and Arnberg, L., 1994, Proceedings of the Fourth International Conference on Aluminum Alloys, Atlanta, pp. 91-98

[48] Flemings, M.C., 1959, AFS Trans., 67, pp 496-

[49] Lloyd, D.J., 1989, Compos. Sci. Technol., 35, 159-179
[50] Kolsgaard, A., 1993, Ph.D. Thesis, NTNU University of Science and Technology

[51] Sahoo, K.L.and Sivaramakrishnan, C.S., 2003, J. Mater. Process. Technol., 135, 253-257

[52] Yarandi, F.M., Rohatgi, P.K. and Ray, S., 1992, AFS Trans., 153, 575

[53] Surappa, M.K.and Rohatgi, P.K., 1981, Met. Trans. B, 12B, 327

[54] Einsten, A., Ann. Phys., 1911, 34, 591

[55] Carity, R.E., 1990, AFS Trans., 152,743

[56] Gowri, S.and Samuel, FH., 1992, Effect of cooling rate on the solidification behaviour of Al-7Pct Si- SiCp metal matrix composites. Metall Trans A, 23, 3369-76

[57] Stefanescu, D.M., 2002, Science and Engineering of Casting Solidification, Kluwer Academic/Plenum Publishers, New York, 311-319

[58] Campbell, J., 1991, Castings, Butterworth Heinemann, 130-131 